\title{
Remediation of Heavy Metal Pollution in Soil by Microbial Immobilization with Carbon Microspheres
}

\author{
Xiaohui Sun, Jing Meng, Shengnan Huo, Jianhua Zhu, and Shichao Zheng
}

\begin{abstract}
Cultivate resistant strains in soil contaminated with heavy metals, improve the survival rate of strains in microbial remediation, and use the interaction between resistant strains and contaminated soil to achieve the purpose of remediation of heavy metal pollution in soil. Using carbon microspheres as the carrier of bacterial strains, the bacterial strains were fixed reasonably and the survival rate was high, which was conducive to the formation of stable bacterial colonies and the reduction of heavy metal pollution.
\end{abstract}

Index Terms-Heavy metal pollution, resistant strain, carbon microspheres.

\section{INTRODUCTION}

Soil is the central link that connects the organic, inorganic, biological and non-biological worlds. It is an important place for the exchange of material energy in the ecosystem [1]. According to the soil pollution survey report released by the ministry of environmental protection and the ministry of land and resources in 2014, about 16.1 percent of China's soil has been polluted. Nowadays, pollution of soil, air and water with heavy metals is increasing rapidly. About 1,400,000 locations in western Europe are highly polluted by heavy metals [2]. Land pollution is also a huge challenge in China, where one-sixth of heavy metal contamination of arable land due to erosion and desertification, more than $40 \%$ of the land has been degraded to varying degrees [3]. In India, Pakistan and Bangladesh, soil and water pollution is serious, where small-scale industrial units waste water is poured into the untreated surface water, in these countries, sewage is typically used in the production of vegetables near large cities. Heavy metal pollution in the environmental samples like soil, air and water is becoming a worldwide problem [4]. Among all types of soil pollutants, mining and smelting operations, burning of fossil fuels, municipal wastes, and agrochemical usage [5], [6], heavy polluting enterprises, mining areas, industrial parks, heavy metal wastewater irrigation, industrial waste residue stacking, atmospheric subsidence and fertilizer containing heavy metals are important sources of soil heavy metals [7], [8]. Compared to organic pollutants, heavy metals can not be degraded, and their mobility in soil is affected by soil conditions, metal morphology and solubility in water. Metal pollution of soil

Manuscript received September 2, 2019; revised November 13, 2019. Xiaohui Sun and Jing Meng are with Shandong Institute of Food and Drug in Section, China (e-mail: sunxiaohui0312@163.con, Mengjing201@163.com).

Shengnan Huo, Jianhua Zhu, and Shichao Zheng are with Shandong Institute of Food and Drug Inspection, Jinan, China (e-mail: huosn@163.com, zhujianhua09@sina.com, zhshch2002@163.com). will lead to loss of soil functions such as buffering, filtering and transformation capabilities, and may lead to pollution of groundwater and surface water [9]. High levels of heavy metals in the soil affect soil fertility and plant growth [10].

The waste products containing heavy metals in the environment postures a trivial threat to public safety and health [11], [12]. These metals in the environment may caused many problems throughout the food chain [13], [14]. firstly, the impairment of the biological activity of soils due to metal loading leads basically to a reduction in decomposition and turnover rates of organic matter. On the other hand, Heavy metals are not biodegradable in soil and tend to accumulate in plants, eventually entering the human body and harming human health [15], [16], It's a serious problem worldwide, Thus, the remediation of heavy metal polluted soils is of high importance.

Microbes can be isolated from various ecological situation, also can grow with extreme environmental conditions such as extreme heat or cool temperatures, harsh aerobic or anoxic desert conditions, Microbes growth only needs energy and carbon sources [17]. Metal plays very important roles in the cultivation and life progression of microorganisms. some metals like calcium $(\mathrm{Ca})$, sodium $(\mathrm{Na})$, nickel $(\mathrm{Ni})$, zinc $(\mathrm{Zn})$, manganese $(\mathrm{Mn})$, copper $(\mathrm{Cu})$, and magnesium $(\mathrm{Mg})$ are necessary for redox reactions, but there're many metals have no biological role and they are not required during the process, like gold $(\mathrm{Au})$, mercury $(\mathrm{Hg})$, cadmium $(\mathrm{Cd})$, silver $(\mathrm{Ag})$ and aluminum $(\mathrm{Al})$. Microbial remediation of heavy metals takes place in this environment. Studies showed that the microbial bioremediation is a feasible, ecological friendly and cost effective technology [18]. Microbial activity has also been shown to play an important role in heavy metal remediation of soils in many ways [19], [20]. Microbial metal uptake is usually carried out in an active or passive manner, Here, we discuss the microbial degradation of heavy metals in soil and prospects for the bioremediation of carbon microspheres.

\section{Heavy Metal Pollution In SoIL}

The increasing use of metal mining and metal industry has resulted in local high pollution and large area heterogeneous, low to medium metal pollution [21]. heavy metals in polluted soils mainly include elements of biotoxicity such as tin, lead, chromium and metalloids, as well as zinc, copper and nickel with certain toxicity, mainly from pesticides, wastewater, sludge and atmospheric deposition. The actual soil pollutants are not single, often complex and diversified, different types of pollutants will interact, comprehensive and associated, Among them, 
organic pollutants and inorganic pollutants constitute the most common compound pollution [22].

Excessive heavy metals can cause physiological dysfunction and malnutrition in plants. High concentrations of metals in the soil often disrupt chemical balance and impair the function of individual ecosystems. The growth of high concentrations of heavy metals in the soil will have a negative impact on crops, because these heavy metals can interfere with the metabolism of plants, including physiological and biochemical processes. Photosynthesis, respiration and degradation of major organelles, even leading to plant death, Excessive intake of metals by plants can cause toxicity in human nutrition and cause acute and chronic diseases [23]. High concentrations of metals in the soil often disrupt chemical balance and impair the function of individual ecosystems. Metal accumulation in the soil results in inhibition of microbial growth conditions. The basic physiological functions of microorganisms involved in the decomposition and transformation of organic matter are impaired $^{[24]}$. Heavy metal contaminated soil may also cause changes in soil microbial community composition, adversely affecting the soil, Heavy metal pollutants have little mobility in the soil, are not easy to be leached with water, are not degraded by microorganisms, and are potentially harmful after entering the human body through the food chain. For example, $\mathrm{Cd}$ and $\mathrm{Zn}$ can lead to acute respiratory and gastrointestinal damage and acute heart, brain and kidney damage [25].

The pollution of heavy metals to the environment, namely soil, water, plants and air, has received much attention due to its potential impact on human and animal health. We need to develop cheap and effective technology to protect valuable natural resources and biological life. However, geotechnical engineering methods provide a good solution for locally highly polluted areas, and the restoration of large landscapes with low metal content in soil but still harmful may be easy to carry out biotechnological restoration. Here, We discussed the potential of microbial processes to assist heavy metal contaminated soils.

\section{TRADITIONAL HEAVY METAL REMOVAL TECHNOLOGY}

Metals that are harmful to the environment, or metals of technical importance, strategic or economic value, must be removed or recycled from their sources using appropriate treatment systems. although many processes for heavy metal removal/recovery have been studied, The most widely used method for removing heavy metals from solution is chemical precipitation [26]. Ion exchange, membrane technology, flocculation and coagulation, flotation, electrodialysis. The traditional heavy metal removal process has the disadvantages of low metal ion removal efficiency, high reagent requirements, high cost, and toxic sludge generation [27].

\section{TyPES INVOLVED IN MiCROBIAL REMEDIATION}

Compared with the conventional method for removing toxic heavy metals, low cost biological adsorption process, a chemical to be treated and / or minimize the volume of biological sludge, metal selectivity advantages. These advantages have become the main motivation for developing biosorption processes to treat soils contaminated with toxic heavy metals. In addition, the growing demand for more environmentally friendly and economical technologies has led to the search for low-cost alternatives to heavy metal processing. In view of this, microbial remediation have become an environmentally friendly and economical choice. Cost effective, metal selective, regenerative, minimization of sludge generation is the advantage of microbial remediation.

Microbial transformation of metals and minerals is an important part of the natural biosphere process and may have beneficial or harmful consequences for human society. A multidisciplinary approach is needed to increase our understanding of this important microbiology field and to make effective use in bioremediation and other biotechnology applications. The types of microbial bioremediation contains two methods: One is in situ bioremediation, which occupies the local treatment of a pollutant, This method allows microbes to come into direct contact with the contaminant where they are in. The process uses dissolved and submerged contaminants as the substrate for reduction. But it is also a slow approach. The other one is the method exploits specifically designed treatment facility such as bioreactors. It is also considered a more effective method than in situ bioremediation.

\section{Process InVOLVED In MicRobial REMEDIATION}

Heavy metals can not be completely eliminated from the surroundings, but they must be converted to a non-toxic stable form. there are lots of traditional methods used for remediation of heavy metals from polluted environmental samples, such as electroplating, ion exchange, membrane filtration, Although those techniques may also expensive, The use of a variety of microorganisms to repair heavy metals has been a challenge [28]. For the past few years, The researchers provided insights into the potential of environmental remediation by native microbial bioremediation [29].

However, Microbial bioremediation of heavy metals is an effective technique. Microbial bioremediation is a highly efficient environmental friendly procedure which also reduces the cost of clean up process associated with heavy metal contamination [30], [31]. New methods of removing heavy metals are being developed and most of recent progress has been made.

\section{STUDY ON BIOREMEDIATION AND APPLICATION OF HEAVY METALS BY MICROORGANISM}

Microbial remediation method reduces the toxicity of pollutants by microbial absorption, precipitation and redox of pollutants, and its repairing characteristics are derived from its own defense mechanism [32]. There are many kinds of microorganisms in the soil, large in quantity, wide in distribution, and there is no natural extinction. Once 
favorable growth conditions are reached, a few residual microorganisms will rapidly multiply at an alarming rate. Compared to higher organisms, microorganisms of great specific surface, The large surface area permits not only the efficient uptake of nutrients and the release of metabolic waste products, but the interaction with the mobile metal fraction of the environment as well [33]. Although the cell membrane structures of Gram-negative bacteria and Gram-positive bacteria are different, the bioabsorbability is comparable due to the similar functional group composition suitable for binding to (metal) cations [34]. The two purposes of the bioremediation process are to degrade heavy metal contaminants and improve soil fertility. microbial isolates from contaminated soil behave remarkably differently [35], As a result of metal toxicity, Inferior bacteria may be inactivated; Nevertheless, Dominant bacteria isolated from contaminated soil can better adapt to the polluted environment, In addition, Research into the bioadsorption and resistance of microorganisms that thrive in metal environments can not be ignored [36].

Compared with other methods, microbial remediation has the advantages of small disturbance to the environment, small secondary pollution, various forms, simple operation, low treatment cost, high efficiency and the ability to treat low-concentration harmful pollutants in situ [37]. Microbial bioremediation technology has a far-reaching development prospect after more than 40 years of development, showing great potential in environmental governance.

\section{AdVANTAGES OF IMMOBILIZED MICROORGANISM TECHNOLOGY}

Compared with free microbes, the advantages of immobilized microbial technology lie in the following aspects: 1) Can improve the cell biological stability; 2) Reduce the pollution of the extreme $\mathrm{pH}$ and harmful substances in soil on microbial mischief, and ensure stable exist in a complex environment, thus exerting high efficiency; 3) Reduce the vicious competition with native bacteria and avoid consumed by phage; In view of the advantages of immobilized microorganism technology, adding to the pollution free high efficient degradation bacteria and indigenous bacteria in the soil of vicious competition will be resolved, making it easier to adapt to the environment, so as to achieve the purpose of efficient repair contaminated soil [38], [39].

\section{PROSPECT CARBON MicrosPHERES CARRIERS BIOREMEDIATION}

Microbial remediation technology refers to the process of removing pollutants from soil and water through the action of microorganisms, or making pollutants harmless. Carbon microspheres have attracted much attention due to their good morphology, high thermal conductivity, good heat resistance, and stable physical and chemical properties. They are extremely attractive in many fields such as electromagnetism, biology, physics, chemistry, and materials science. To use carbon microspheres carrier as effective parts of filter materials in bioremediation processes for cleaning heavy metal contaminated in different environments, the pH-stability of the biological components, the possibility of a repeated use of the carbon microspheres carrier and the immobilization of the biocomponents are of special importance. carbon microspheres carrier allows the immobilization of various microorganisms without loosing theiractivity. Other advantages of carbon microspheres carrier are a high mechanical, Environment-friendly and pollution-free, short reaction time, simple operation, good repeatability. Due to the high stability of the carbon microspheres Other advantages of carbon microspheres carrier ceramics are a high mechanical, the safe immobilization of the biocomponents, the carbon microspheres carrier are well suited for the remediation of heavy metal pollution in soil by microbial immobilization for bioremediation purposes. However, there is very little literature on the use of carbon microsphere immobilization to study bioremediation.

\section{Degradation of Heavy Metal Contaminated SoIL BY CARBON MICROSPHERES}

Existing techniques for microbial remediation of soils contaminated with heavy metals usually involves seeding the soil directly with microbes. This method strain is not easy to fix, and the survival rate is low, which leads to the poor effect of microbial remediation, and the degree of soil pollution is difficult to improve, Carbon microsphere fixation method can better solve the above problems [40]. This review will focus on the discussion of microbial bioremediation processes and provide carbon microspheres as the carrier of the bacterial strain, The interaction between the resistant bacterial strain and the contaminated soil was used to achieve the purpose of remediation of soil heavy metal pollution.

The carbon microsphere fixation method for remediation of heavy metal contaminated soil includes the following steps:

1) Soil sample collection: $10 \mathrm{~g}$ of soil was taken from the heavy metal contaminated soil for later use.

2) Preparation of soil diluent: according to the soil of $2 \mathrm{~g}$, add $198 \mathrm{ml}$ sterile water triangle in a bottle, uniform oscillation, is the soil suspension diluted $10^{-2}$. Then 10 -fold gradient dilution was carried out to prepare soil diluents of $10^{-3}$ to $10^{-7}$ degrees of dilution.

3) Medium plate preparation: according to the culture medium formula each configuration, Beef paste Peptone Agar Medium , Gao's No.1 medium, Martin's medium $(2 \mathrm{ml}$ sodium deoxycholate $(2 \%)$ and $0.4 \mathrm{ml}$ 10,000 units $/ \mathrm{ml}$ streptomycin were added to the martensite medium, gause I medium sterilization before add 10 drops of $10 \%$ phenol).

4) Inoculation: use sterile straw to absorb $0.1 \mathrm{ml}$ of soil diluent of corresponding concentration, and inoculate it on the plate with aseptic operation technology, and evenly spread it. Choose three vaccination in Beef paste Peptone Agar Medium, Gao's No.1 medium, Martin's medium.

5) Cultivating: bacterial tablet in $37^{\circ} \mathrm{Cconstant}$ temperature 
culture $1 \sim 2 \mathrm{~d}$, actinomycetes in $30^{\circ} \mathrm{C}$ to develop $2 \sim 3 \mathrm{~d}$, mold in $30^{\circ} \mathrm{C}$ to develop $3 \sim 5 \mathrm{~d}$, get strains.

6) Preparation of carbon microspheres: Adding glucose, mannose and xylose, deionized water dissolved, mixed with iron trichloride, moved to the reaction kettle,

$150-200^{\circ} \mathrm{C}$ in the vacuum drying oven, water fluid $10-15$

$\mathrm{h}$, after washing, filtering, drying under $70-100{ }^{\circ} \mathrm{C}$ for 10 to $15 \mathrm{~h}$, get carbon microspheres.

7) )Flask culture: Preparation of liquid medium, will get the step (6) to join the liquid medium, carbon microspheres will step (5) of the strains inoculation to the liquid medium, At 130-170rpm, the corresponding culture temperature and time were used for the culture of bacteria, actinomycetes and fungi, and the bacterial turbidity solution was obtained.

8) Preparation of bacterial suspension: The bacterial turbid solution obtained in step (7) was centrifuged for $10-15 \mathrm{~min}$ and then the supernatant was discarded to obtain the suspension solution.

9) Microbial release: The suspensions obtained in step (8) were mixed with uncontaminated soil and distributed to the soil contaminated by heavy metals.

The study of microbial behavior in metallic environments is an important part of earth microbiology. The influence of microorganisms on the fate of minerals and geological compounds is of primary interest to the field. The advantage of carbon microsphere fixation is:

1) Taking the soil in the heavy metal contaminated area as the target, the resistant strain in the heavy metal contaminated soil was obtained to improve the survival rate of the strain in the microbial remediation, and the interaction between the resistant strain and the contaminated soil was used to achieve the purpose of remediation of heavy metal pollution. In the whole process, the screening and identification of bacterial strains are avoided, and new strains are not needed to be introduced. The operation is simple and convenient.

2) Monodisperse carbon microspheres with particle sizes of $5-10 \mu \mathrm{m}$ were prepared by using glucose, xylose and mannose as carbon sources without adding template and surfactant. As the carrier of bacterial strains, carbon microspheres were reasonably fixed and had a high survival rate, contributing to the formation of stable bacterial colonies and the reduction of heavy metal pollution.

\section{Conclusions and Future Perspectives}

Because of these factors, it provides a viable alternative to expensive physical-chemical methods for decontaminations. The microbial bioremediation process has the ability to degrade the inorganic pollutants, such as heavy metals, that are harmful and poisonous, by means of the absorption, accumulation or absorption of heavy metals by microorganisms. Especially in the field of microbiology, a wide range of methods and techniques and interdisciplinary studies are needed to improve the degradation efficiency of heavy metal contaminated soil. Especially for the powerful interdisciplinary field of geological microbiology from microbes to minerals, a broad range of methods and techniques and interdisciplinary research are needed. However, this field requires a lot of basic research and holds much promise for the future development of applied science. In short, the bioremediation technology using carbon microspheres to immobilizing resistant strains is applied to the purification of toxic heavy metals. As an environmental protection clean technology, it has gained more significance and more important value in the field of heavy metal contaminated soil remediation technology.

Microorganisms have a certain impact on the distribution of metals in the environment. For bioremediation technologies that pollute the environment, the basic knowledge of good and effective metal bioremediation mechanisms provides a theoretical basis for the development of commercially viable biosorbents.Although it has been established biological carbon microspheres metal bioremediation methods to fight heavy metal pollution anthropogenic and natural sources, but their application is not widespread. It is time to launch a more comprehensive interdisciplinary approach between biotechnologists and metallurgists to bring laboratory-scale bioremediation processes into land-scale technologies that will be acceptable for industrialists.

\section{CONFLICT OF INTEREST}

The authors declare no conflict of interest

\section{AUTHOR CONTRIBUTIONS}

Xiaohui Sun and jing Meng collect relevant literature; Shengnan Huo responsible for Preliminary data collection; Jianhua Zhu Check the possibility of the paper; Xiaohui Sun and Shengnan Huo conducted the research; jing Meng and Shichao Zheng had analyzed the data; Xiaohui Sun and jing Meng wrote the paper; all authors had approved the final version.

\section{REFERENCES}

[1] S. P. McGrath, F. J. Zhao, and E. Lombi, "Plant and rhizosphere processes involved in phytoremediation of metal-contaminated soils," Plant Soil, vol. 232, pp. 207-214, 2001.

[2] Y. Liu, Shrinking Arable Lands Jeopardizing China's Food Security, 2006.

[3] C. Wang, X. Liu, J. Guo et al., "Biodegradation of marine oil spill residues using aboriginal bacterial consortium based on, Penglai 19-3, oil spill accident, China," Ecotoxicolngy and Environmental Safety, vol. 159, pp. 20-27, 2018.

[4] A. R. Memon and P. Schröder, "Implications of metal accumulation mechanisms to phytoremediation," Env Sci Pollut Res., vol. 16, pp. 162-175, 2009.

[5] G. Haferburg and E. Kothe, "Metallomics: Lessons for metalliferous soil remediation," Appl Microbiol Biotechnol., vol. 87, pp. 1271-1280, 2010.

[6] Z. Hassan and M. G. M. Aarts, "Opportunities and feasibilities for biotechnological improvement of $\mathrm{Zn}, \mathrm{Cd}$ or $\mathrm{Ni}$ tolerance and accumulation in plants," Env Exp Bot, vol. 72, pp. 53-63, 2011.

[7] J. O. Nriagu, "Global metal pollution. Poisoning the biosphere," Environment, vol. 32, pp. 7-33, 1990.

[8] M. A. Cole, "Solubilization of heavy metal sulfides by heterotrophic soil bacteria," Soil Science, vol. 127, pp. 313-317, 1979.

[9] T. Vamerali, M. Bandiera, and G. Mosca, "Field crops for phytoremediation of metal contaminated land. A review," Env Chem Lett., vol. 8, pp. 1-17, 2010. 
[10] L. Yanez et al., "Overview of human health and chemical mixtures: problems facing developing countries," Env Health Perspect, vol. 110 pp. 901-909, 2002.

[11] W. Boer et al., "Response of the chitinolytic microbial community to chitin amendments of dune soils," Biol. Fertil. Soils, vol. 29, pp. 170-177, 1999.

[12] S. Raytapadar, R. Datta, and A. K. Paul, "Effects of some heavy metals on growth, pigment and antibiotic production by Streptomyces galbus,' Acta Microbiol. Immunol. Hung., vol. 42, pp. 171-177, 1995.

[13] A. G. Khan, "Role of soil microbes in the rhizospheres of plants growing on trace metal contaminated soils in phytoremediation," $J$ Trace Elem Med Biol., vol. 18, pp. 355-364, 2005.

[14] V. Sheoran, A. S. Sheoran, and P. Poonia, "Role of hyperaccumulators in phytoextraction of metals from contaminated mining sites: A review," Crit Rev Env Sci Technol, vol. 41, pp. 168-214, 2011.

[15] A. Kapoor and T. Viraraghvan, "Fungal biosorption-An alternative treatment option for heavy metal bearing wastewater: A review," Bioresour Technol, vol. 53, pp. 195-206, 1995.

[16] T. A. Davis, B. Volesky, and A. Mucci, "A review of the biochemistry of heavy metal biosorption by brown algae," Water Res., vol. 37, pp. 4311-30, 2003.

[17] M. Vidali, "Bioremediation: An overview," Pure Appl Chem, vol. 73, no. 7, pp. 1163-72, 2001.

[18] S. Singh, S. H. Kang, A. Mulchandani, and W. Chen, "Bioremediation: Environmental clean-up through pathway engineering," Curr Opin Biotechnol, vol. 19, pp. 437-444, 2008.

[19] D. H. Nies, "Efflux-mediated heavy metal resistance in prokaryotes," FEMS Microbiol. Rev., vol. 27, pp. 313-339, 2003.

[20] K. M. Geetesh, "Microbes in heavy metal remediation: A review on current trends and patents," Recent Patents on Biotechnology, vol. 11, pp. 188-196, 2017.

[21] G. M. Gadd, "Metals, minerals and microbes: Geomicrobiology and bioremediation," Microbiology, vol. 156, pp. 609-643, 2010.

[22] X. Lan et al., "Effect of two leadcadmium tolerant fungi on the fractionation of lead and cadmium in soil, and the accumulation of lead and cadmium in Chinese cabbage," Acta Scientiae Circumstantiae, vol. 36, no. 6, pp. 2095-2102, 2016.

[23] F. Glombitza and S. Reichel, "Metal-containing residues from industry and in the environment: Geobiotechnological urban mining," $A d v$ Biochem Eng Biotechnol, vol. 141, pp. 49-107, 2014.

[24] L. Babák et al., "Biosorption of $\mathrm{Cu}, \mathrm{Zn}$ and $\mathrm{Pb}$ by thermophilic bacteria - effect of biomass concentration on biosorption capacity," Acta Universitatis Agriculturae Et Silviculturae Mendelianae Brunensis $L X$, vol. 1, no. 5, p. 9, 2012.

[25] K. Hrynkiewicz and C. Baum, "Application of microorganisms in bioremediation of environment from heavy metals," Environmental Deterioration and Human Health, Springer, pp. 215-227, 2014.

[26] T. Sreekrishnan et al., "Recent advances in bioremediation of heavy metals and metal complex dyes: Review," Journal of Environmental Engineering, 2015.

[27] H. Eccles, "Treatment of metal-contaminated wastes: Why select a biological process?" Trends Biotech, vol. 17, pp. 462-465, 1999.

[28] R. Kumar et al., "Potential of some fungal and bacterial species in bioremediation of heavy metals," Journal of Nuclear Physics, Material Sciences, Radiation and Applications, vol. 1, pp. 213-223, 2014.

[29] H. Götz and K. Erika, "Microbes and metals: Interactions in the environment," Journal of Basic Microbiology, vol. 47, pp. 453-467, 2007.

[30] M. Zabochnicka-ÅšwiÄ and M. Krzywonos, "Potentials of biosorption and bioaccumulation processes for heavy metal removal," Mercury, vol. 6, p. $145,2014$.

[31] G. M. Gadd and C. White, "Microbial treatment of metal pollution - A working biotechnology?" TIBTECH, vol. 11, pp. 353-359, 1993.

[32] T. Macek and M. Mackova, "Potential of biosorption technology," Microbial Biosorption of Metals, pp. 7-17, 2011.

[33] N. Ahalya, T. Ramachandra, and R. Kanamadi, "Biosorption of heavy metals," Res J Chem Environ, vol. 7, pp. 71-79, 2003.
[34] W. Jiang et al., "Elucidation of functional groups on Gram-positive and Gram-negative bacterial surfaces using infrared spectroscopy," Langmuir, vol. 20, pp. 11433-11442, 2004.

[35] N. Friis and P. Myers-Keith, "Biosorption of uranium and lead by Streptomyces longwoodensis," Biotechnol. Bioeng., vol. 28, pp. 21-28, 1986.

[36] M. U. Mustapha and N. Halimoon, "Microorganisms and biosorption of heavy metals in the environment: A review paper," J Microb Biochem Technol, vol. 7, pp. 253-6, 2015.

[37] D. H Cho, E. Y. Kim, and Y. T. Hung, "Heavy metal removal by microbial biosorbents," Environmental Bioengineering, Springer, vol. 11 , pp. 375-402, 2010.

[38] G. M. Gadd, "Bioremedial potential of microbial mechanisms of metal mobilization and immobilization," Curr. Opin. Biotechnol., vol. 11, pp. 271-279, 2000

[39] M. I. Lone et al., "Phytoremediation of heavy metal polluted soils and water: progresses and perspectives," J Zhejiang Univ Sci., vol. B 9, pp. 210-220, 2008.

[40] M. Reinicke et al., "Multi-metal bioremediation by microbial assisted phytoremediation," Actinobacteria. Application in bioremediation and production of industrial enzymes," CRC, Boca Raton, USA, pp. 87-105, 2013.

Copyright (C) 2020 by the authors. This is an open access article distributed under the Creative Commons Attribution License which permits unrestricted use, distribution, and reproduction in any medium, provided the original work is properly cited (CC BY 4.0).

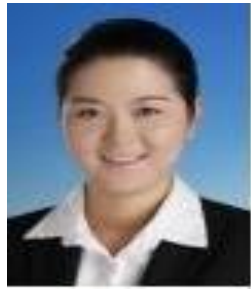

Xiaohui Sun was born in China on May 16, 1990. She received a master's degree of microbiology, Qufu Normal University in 2015. She works in Shandong Institute of Food and Drug Inspection, and is engaged in microbiology research and method development in food and related fields.

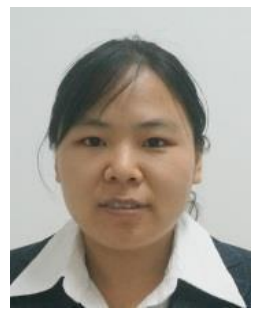

Jing Meng was born in China on July 28, 1979. She received a master's degree of microbiology, Shandong University in 2006. She works in Shandong Institute of Food and Drug Inspection, and is engaged in microbiology research and method development in food and related fields.

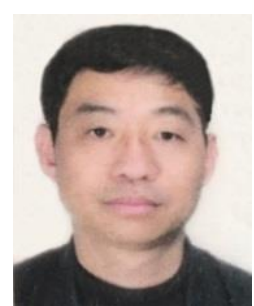

Jianhua Zhu was born in China on Dec. 24, 1962. $\mathrm{He}$ received a master's degree of analytical chemistry, Shandong University in 1987. He is senior researcher at Shandong Institute of Food and Drug Inspection, and is long-term engaged in research and application of analytical chemistry technology in food, pesticide and other fields.

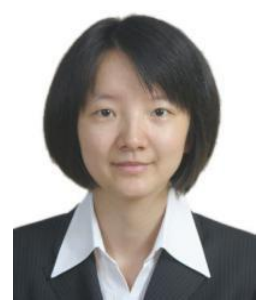

Shichao Zheng was born in China on August 24 1985. She graduated from Kunming University of Science and Technology. She work at Shandong Institute of Food and Drug Inspection, and is engaged research fields of microbiolog, molecular biology in food and related fields. 